\title{
AN EMBODIMENT PERSPECTIVE ON PROTECTION MOTIVATION THEORY: THE IMPACT OF INCIDENTAL WEIGHT SENSATIONS ON THREAT-APPRAISAL, COPING-APPRAISAL, AND PROTECTION MOTIVATION
}

\author{
Kai KASPAR
}

Social and Media Psychology, Department of Psychology, University of Cologne Richard-Strauss-Str. 2, 50931 Cologne, Germany Email:kkaspar@uni-koeln.de

\begin{abstract}
This study shows how the cognitive components of the protection motivation theory (PMT) are affected by embodied information in the context of skin cancer prevention. Weight sensations were manipulated by writing on a light versus heavy clipboard. Heaviness increased the mean self-efficacy of 120 participants and their coping-appraisal but decreased the perceived rewards of maladaptive behaviour. In contrast, weight neither affected the perceived severity of maladaptive behaviour nor the importance of tanned skin. Thus, the results are only partially compatible with the metaphor-oriented approach of embodied cognition. Moreover, increased coping-appraisal, but not threat-appraisal, increased participants' reported protection motivation, while a sensed heaviness increased this correlation. The results suggest enlarging the spectrum of environmental inputs affecting the cognitive parameters of the PMT. The results also raise the question of the validity of self-reports in a pencil-and-paper administration mode and they may indicate the utility of bodily sensations in therapeutic settings.
\end{abstract}

Key words: protection motivation theory, embodied cognition, weight sensations, health behaviour, skin cancer prevention

\section{Introduction}

Health research highlights the myriad ways in which mind and body are closely intertwined (Bishop, 1994). Several cognitive processes constitute our motivation to behave healthily and hence build the scaffold for the health of mind and body. Accordingly, health psychology prevailingly focuses on the mechanisms between mental processes and

Acknowledgements

I would like to thank Gerald Simmert and Daniel

Zimmermann for their help in data acquisition. bodily behaviour (Matarazzo, 1980). However, previous research has neglected the potential impact of basal bodily sensations on cognitions determining health motivation. This is surprising as the theory of embodied cognition suggests a strong bidirectional relationship between bodily experiences and higher cognitive processes (Lee \& Schwarz, 2012). Here, I will demonstrate that this concept is of particular importance for healthy behaviour. With regard to the Protection Motivation Theory (PMT, Rogers, 1983), I present first effects of haptic weight sensations on those factors that constitute our motivation to behave healthily.

DOI: $10.21909 /$ sp.2015.03.701 


\section{Embodied Cognition and Weight}

According to the theory of embodied cognition, higher cognitive processes are strongly linked to sensory and motor processes; that is, the mind's activity is ingrained in the body's interaction with the world (e.g., Wilson, 2002; Kaspar, König, Schwandt, \& König, 2014). Following this perspective, we should extend the so far considered array of environmental inputs influencing one's protection motivation by taking basal bodily sensations into account. Research on healthy behaviour has heretofore neglected this possibility. In contrast to persuasive communications that are commonly used to positively influence the motivation for healthier behaviour, the effect of bodily experiences is much more direct, less ambiguous, and requires less cognitive evaluation (Lee \& Schwarz, 2012).

Current literature on embodied cognition postulates that cognition is grounded on bodily states. According to a developmental perspective, sensorimotor experiences early in life serve as a foundation for the later learning of more abstract concepts. Williams, Huang, and Bargh (2009) labelled this phenomenon as scaffolding because "humans readily integrate incoming information with extant knowledge structures" (p. 1257). Children learn that the interaction with heavy objects requires more physical effort and more cognitive planning than dealing with light objects (Jostmann, Lakens, \& Schubert, 2009). The repeated experience of weight characteristics early in life then provides a scaffold for the later development of abstract concepts such as "seriousness", "importance", and "potency". It is assumed that such established associations between spe- cific sensorimotor sensations and higher cognitive processes do not evaporate over time (Ackerman, Nocera, \& Bargh, 2010). Hence, the bodily experience of weight simultaneously stimulates physical sensations and associated cognitive concepts. Everyday language indeed includes phrases expressing this established relationship such as the idiom "the gravity of the situation" (Ackerman et al., 2010) or an issue that "carries weight" (Schneider, Rutjens, Jostmann, $\&$ Lakens, 2011). Accordingly, several authors refer to the conceptual metaphor theory (Lakoff \& Johnson, 1980) postulating that abstract concepts are represented in a conceptual system by concrete bodily metaphors. This idea also implies that the effect of a specific bodily sensation does not generalize to all abstract cognitions but is limited to those cognitive domains that are conceptually linked to a specific embodied information (Ackerman et al., 2010; Kaspar, 2013).

Recent studies on weight effects provided evidence for this embodiment perspective. The haptic sensation of heaviness, compared to lightness, increased the evaluation of a job candidate's potency and seriousness (Ackerman et al., 2010), the perceived importance of fair decision-making procedures (Jostmann et al., 2009), the importance of the visual attractiveness of others (Kaspar $\&$ Krull, 2013), and the importance of a book's content (Chandler, Reinhard, \& Schwarz, 2012). Moreover, Kaspar (2013) showed that the weight of a clipboard or the weight of real drug packages influenced the evaluation of drug effectiveness, drug side effects, and disease severity. Against this background, the question arises whether haptic weight sensations may also affect the selfreported motivation to behave healthily. The 
PMT provides an established and well-tested model to clarify whether the incidental stimulation by a clipboard (light vs. heavy) can significantly sway individual responses. If this is the case, we will be able to better understand the role of model components and to assess their sensitivity to bodily sensations.

\section{The Protection Motivation Theory}

The PMT was developed on the basis of expectancy-value theories but revisions additionally include self-efficacy and reward components (Rogers, 1983). The PMT emphasizes two independent cognitive processes mediating protection motivation: threat-appraisal and coping-appraisal (Figure 1). Threat-appraisal evaluates maladaptive behaviour (e.g., extensive sun exposure). On the one hand, threat-appraisal includes one's perception of threat constituted by the perceived severity of maladaptive behaviour (e.g., how damaging and life-threatening skin cancer is) and by one's perceived vulnerability to its negative consequences. Both components increase the likelihood of a healthier behaviour (e.g., reducing sunbathing). On the other hand, threat-appraisal also comprises the evaluation of rewards, which are associated with the continuance of maladaptive behaviour (e.g., enjoying to have others notice and compliment one's tan) and hence reduce the likelihood of protective behaviour. The coping-appraisal involves the assessment of self-efficacy in carrying out adaptive protection behaviour (e.g., the confidence that one can effectively use sunscreen) as well as perceived response-efficacy (e.g., perceived effectiveness of sunscreen usage in preventing skin cancer). Both factors increase the likelihood to show the recommended behaviour, but this likelihood is reduced by the extent of the perceived response costs (e.g., inconvenience of sunscreen). Both, the threat- and the copingappraisal, ultimately lead to the motivation to show a certain protection behaviour. Meta-

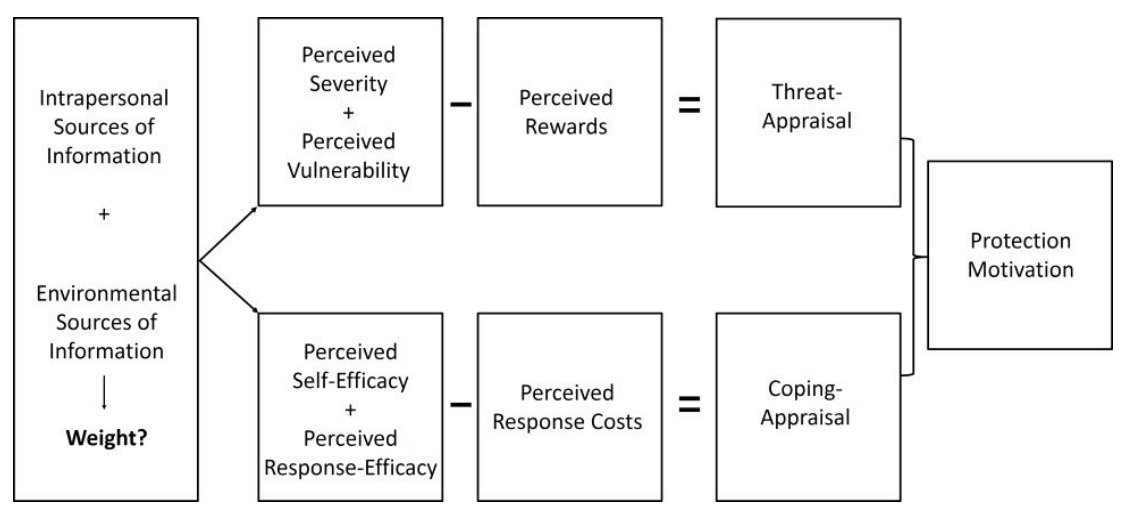

Figure 1 Model of the PMT including weight as a potential environmental source of information. 
analyses (Floyd, Prentice-Dunn, \& Rogers, 2000; Milne, Sheeran, \& Orbell, 2000) demonstrated that the PMT reliably explains the psychological components of protection motivation. All variables of the PMT showed effects of moderate size in the predicted directions. Thus, the variables of the PMT provide a suitable basis to promote desirable healthy behaviour.

As noticed by Pechmann, Zhao, Goldberg, and Reibling (2003), research commonly focuses on the question of how to influence the magnitude of the PMT's cognitive variables positively and, in the end, to improve the motivation for healthier behaviour. In this context, Norman, Boer, and Seydel (2005) pointed out that the revision of the original model by Rogers (1983) "extended the theory to provide a more general account of the impact of persuasive communications, with an emphasis on the cognitive processes that mediate behaviour change" (p. 81). Indeed, in studies referring to the PMT, participants are commonly confronted with communications (verbal and/or pictorial) designed to positively manipulate the variables of the PMT. The content of these persuasive communications is framed towards the specific domain, but inputs to the model include environmental as well as intrapersonal sources of information affecting the magnitude of the PMT variables (see Figure 1). According to several authors (Floyd et al., 2000; Milne et al., 2000; Rogers, 1983), the intrapersonal sources comprise personality aspects and prior experiences with similar threats (including feedback from coping activity). The environmental sources include observational learning and verbal persuasion (especially fear appeals) that is sometimes combined with pictorial messages (Pechmann et al., 2003).

\section{The Present Study}

All in all, according to the PMT, changes in the motivation to behave in a healthier way, such as proper skin cancer prevention, derive from high-level evaluation processes. These evaluation processes comprise threatand coping-appraisal, including the perception and interpretation of various inputs such as persuasive communication. Against this background, the question arose whether we will find changes in individuals' self-reported protection motivation elicited by incidental and very subtle bodily experiences instead of the common persuasive communication. This possibility is strongly proposed by current research in the field of embodied cognition and it will bring a new factor into the PMT.

Indeed, it seems likely that the haptic sensation of heaviness may influence some cognitive variables of the PMT, leading to a change in one's coping- and threat-appraisal. The PMT variable self-efficacy is one aspect of coping-appraisal that can be described in terms of potency and effectiveness. Potency-related concepts are characterized by a strong conceptual link to physical heaviness and were found to increase when subjects held a heavy versus light clipboard in their hands (Ackerman et al., 2010; Jostmann et al., 2009; Kaspar, 2013). Moreover, selfefficacy ratings are related to oneself. Consequently, the embodied information of potency in the form of physical heaviness may stimulate the impression of one's own selfefficacy. A similar conceptual link exists between weight and response-efficacy, but the latter does not refer to the evaluator. Hence, weight may show an attenuated effect in this case. In contrast, no direct conceptual link 
exists between weight and the perceived response costs so that a weight effect is unlikely in this case. Hence, I hypothesized:

H1: The haptic sensation of physical heaviness compared to lightness increases both the perceived self-efficacy and the overall coping-appraisal.

Moreover, heaviness should increase the perceived severity of maladaptive behaviour. According to the metaphor-oriented approach of embodied cognition, heaviness is linked to the concept of seriousness and severity (e.g., Jostmann et al., 2009). Correspondingly, Kaspar (2013) showed that the perceived severity of several diseases was rated higher when subjects held a heavy versus light clipboard in their hands. The same effect is expected to occur in the context of the PMT. Additionally, heaviness should decrease perceived rewards. If embodied cues, such as weight, actually trigger corresponding cognitive associations, the bodily experience of lightness will stimulate reward-related cognitions (and heaviness will hamper them). Rewards make things "light" or easier to do. Hence, cognitions about rewards, on the one hand, and the bodily sensation of heaviness, on the other hand, are incompatible. This incongruity possibly reduces the rating of rewards - and consequently threat-appraisal. The terms "light" and "easy" even have the same semantic meaning for our German sample, so a strong metaphorical relation probably mediates this interrelation as suggested by the metaphor-oriented approach of embodied cognition (cf. Ackerman et al., 2010; Kaspar \& Vennekötter, 2015). Consequently, I hypothesized:

H2: When subjects hold a heavy versus light clipboard in their hands, the perceived severity of maladaptive sunbathing in- creases, rewards decrease, and threat-appraisal increases.

According to the revised model of the PMT (Rogers, 1983), coping-appraisal and threatappraisal should be additively combined to infer protection motivation. Hence, we will observe a positive effect of weight on inferred protection motivation if both appraisals are sufficiently affected by weight in the expected direction (i.e., increased copingand threat-appraisal). In contrast, the effects of weight on both appraisals will cancel each other out, if the effect is similar in size but, in contrast to the expectation, oppositely related.

H3: Heaviness versus lightness increases the inferred protection motivation.

Finally, protection motivation can be assessed directly by asking participants to report their motivation to perform proper skin cancer prevention (Prentice-Dunn, McMath, $\&$ Cramer, 2009). By means of a regression model, I intended to test which of the two appraisals explain the reported protection motivation and if the incidental sensation of weight moderates this effect. Accordingly, I stated:

H4: A significant amount of variance in the reported protection motivation can be explained by coping-and threat-appraisal, while weight is a moderator variable in this model.

In addition to the parameters of the PMT, I investigated two social comparisons. On the one hand, I examined whether incidental weight sensations influence the reported importance of tanned skin in comparison to the peer group. On the other hand, I examined whether the perceived properness of one's own skin cancer prevention, compared to the skin cancer prevention of others, is influenced by the clipboard's weight. The 
former measure should be increased in the heavy clipboard condition due to the conceptual link between importance and physical heaviness (Jostmann et al., 2009; Chandler et al., 2012). In contrast, the latter measure should not be affected by weight since the concepts of properness and physical weight do not share a clear conceptual overlap. Hence, I intended to test whether the impact of weight on social comparisons, if existent, generalizes to a comparison that is not conceptually related to physical weight:

H5: A heavy versus light clipboard increases the perceived importance of tanned skin in a social comparison, whereas the reported properness of skin cancer prevention is not affected by weight.

\section{Methods}

\section{Participants and Procedure}

120 participants ( 60 females) with an average age of 24.23 years $(S D=4.75)$ were included in the study. Passers-by walking alone on the university campus were approached by one of two experimenters who were naïve to the hypotheses but aware of the different weights of the clipboards. Participants were pseudo-randomly assigned to either a light or heavy clipboard. Gender was counterbalanced across conditions (light: 30 male, 31 female; heavy: 29 female, 30 male) and served as a covariate due to gender differences in skin cancer prevention (Mermelstein \& Riesenberg, 1992). Age served as a second covariate due to potential age differences in sunbathing frequencies (Schneider \& Krämer, 2010). Since the actual knowledge about the critical topic may bias the effect of the clipboard's weight (Chandler et al., 2012), passers-by who reported a case of skin can- cer in their family or among their relatives were excluded $(n=21)$. This exclusion criteria was defined prior the beginning of the study and was measured by a corresponding item. One additional female subject was excluded as she did not report her age. Thus, 120 participants remained in the final sample. The target sample size was a priori determined on the basis of ten effect sizes reported by previous studies that examined the effect of a clipboard's weight: Ackerman et al. (2010) reported a weight effect on the perceived suitability of a job candidate $(d=0.54)$ and the importance of a task $(d=0.61)$. Jostmann et al. (2009) reported a weight effect on the perceived value of a currency $(d=0.71)$ and on the importance of fair decision-making procedures $(d=0.61)$. Kaspar (2013) reported six weight effects on effectiveness and severity ratings (Study 1: $d=0.91$ and $d=1.05$; Study 2: $d=0.65$; Study 3: $d=0.58$; Study 4: $d=0.42$; Study 5: $d=0.63$ ). Thus, the average $d$ was 0.67 . The required sample size was calculated using the G*Power software (Faul, Erdfelder, Lang, \& Buchner, 2007). Given a $d$ of 0.67, a significance level of .05, two-tailed hypothesis testing, and a power of .95 , the target sample was $n=59$ per weight condition for a group comparison or, alternatively, a total sample of $n=119$ to find an effect of a single regression coefficient in a multiple regression analysis based on seven predictors (see Results).

At the beginning of the study, participants were informed that all data will be stored and processed anonymously and that completion of the survey was considered to indicate consent. Afterwards, participants were instructed to do the survey on skin cancer protection by a cover sheet. Then, they provided some personal data (age, gender, native language, skin cancer in family or among 
relatives). Afterwards, they filled out the questionnaire measuring the PMT variables and their motivation to perform skin cancer prevention. Finally, participants compared themselves to others regarding skin cancer protection and the importance of tanned skin (social comparisons).

\section{Materials}

The weight of the two clipboards was selected according to other studies (Ackerman et al., 2010; Kaspar, 2013; Kaspar \& Krull, 2013; Kaspar, Jurisch, \& Schneider, 2015), with a light clipboard of $318 \mathrm{~g}$ and a heavy counterpart of $1609 \mathrm{~g}$. A self-report questionnaire by Prentice-Dunn and colleagues (McMath \& Prentice-Dunn, 2005; PrenticeDunn et al., 2009) measured the six core parameters of the PMT, namely severity (e.g., "People who deliberately sunbathe greatly increase their risk of skin cancer"), vulnerability (e.g., "My chances of developing skin cancer are zero"), rewards (e.g., "I enjoy having others notice and complement my tan"), self-efficacy (e.g., "I know that I can effectively use sunscreen each and every time I sunbathe"), response-efficacy (e.g., "Using sunscreen will definitely help prevent me from developing skin cancer"), and response costs (e.g., "Protecting myself from the sun's ultraviolet waves requires a considerable amount of effort"). Each core parameter was assessed by at least five items, which were presented in a 10-point Likert-format (1-10), while some items were inverted. The internal consistencies of the scales were very similar to those observed in previous studies, with alphas ranging from .69 (severity) to .77 (response costs). Protection motivation was measured with four items $(\alpha=.65)$, for example "I will forego extensive sunbathing in the future". Participants also assessed their current sun protection behaviour compared to others on a single item ("In contrast to others, how thoroughly do you think you protect yourself from the sun?"), as well as the importance of tanned skin in a social comparison ("In contrast to others, how important do you think tanned skin is for you?"). Both items were bipolar, ranging from "worse/ less important" to "better/more important" $(-5$ to +5$)$.

\section{Data Analysis}

The PMT parameters were additively combined (Rogers, 1983; Norman et al., 2005). Threat-appraisal was defined by the average score across severity and vulnerability, minus the rewards ${ }^{1}$. The coping-appraisal was computed by means of self-efficacy and response-efficacy, minus the response costs. In addition to the motivation for protection behaviour that was explicitly measured (reported protection motivation), I also inferred the protection motivation (inferred protection motivation) on the basis of both appraisal types by their mean values. In this context, the view that threat must occur prior to the evaluation of coping options (Floyd et al., 2000) was also considered. As far as

\footnotetext{
${ }^{1}$ In some literature (Floyd et al., 2000; Norman et al., 2005) the difference between the combination of severity and vulnerability, on the one hand, and the rewards of a maladaptive behaviour, on the other hand, is reversely conceptualized: severity/vulnerability is subtracted from rewards. Hence, a positive difference indicates a tendency to perform the maladaptive behaviour. In contrast, here the rewards were subtracted from severity/vulnerability so that a positive difference indicates an enhancing effect on the protection motivation.
} 
the rewards exceeded the combination of perceived severity and vulnerability, the protection motivation was automatically adjusted to zero.

\section{Results}

Initially, a MANOVA was calculated, incorporating the clipboard's weight as independent variable, gender and age as covariates, and the six core parameters of the PMT as dependent variables (i.e., severity vulnerability, rewards, self-efficacy, response-efficacy, and response costs). The MANOVA showed a significant main effect of weight, Wilks's Lambda $=.16, F(6,111)=$ $3.53, p<.01, \eta_{\mathrm{p}}{ }^{2}=.16$, but no significant effect of age, $p=.16$, and gender, $p=.10$. Each dependent variable was subsequently analysed by means of a corresponding ANOVA.

In the first step, I analysed the impact of weight on the components of coping-appraisal. As assumed in H1, the clipboard's weight affected the reported self-efficacy, $F(1,116)=13.97, p<.001, \eta_{p}^{2}=.11$, with higher values when subjects held a heavy clipboard in their hands (Table 1). No weight effect was found regarding the perceived response costs, $F(1,116)=2.07, p=.15, \eta_{\mathrm{p}}{ }^{2}=$ .02 , and the reported response-efficacy, $F(1,116)=0.28, p=.60, \eta_{\mathrm{p}}^{2}<.01$. In the next step, I aggregated these three components to assess the overall coping-appraisal that was analysed using the same ANOVA model. The results showed an effect of the clipboard's weight, $F(1,116)=5.24, p=.02$, $\eta_{\mathrm{p}}{ }^{2}=.04$. As predicted, the enhancing effect of the clipboard's weight on self-efficacy led to increased coping-appraisal when participants held a heavy clipboard in their hands.
Next, the components of the threat-appraisal were analysed. In contrast to $\mathrm{H} 2$, the clipboard's weight did not affect perceived severity, $F(1,116)=0.55, p=.46, \eta_{\mathrm{p}}{ }^{2}<.01$. Also, no effect on perceived vulnerability was found, $F(1,116)=0.15, p=.70, \eta_{\mathrm{p}}^{2}<.01$. But as expected, perceived rewards were higher when subjects held a light versus heavy clipboard in their hands, $F(1,116)=$ $5.71, p=.02, \eta_{\mathrm{p}}^{2}=.05$, (see Table 1$)$. These three components were then aggregated to assess the overall threat-appraisal but no significant effect of the clipboard's weight was revealed, $F(1,116)=1.89, p=.17, \eta_{\mathrm{p}}^{2}=$ .02 . Hence, the exclusive effect of the clipboard's weight on perceived reward was not strong enough to significantly influence the overall threat-appraisal according to the PMT.

The protection motivation was analysed in the subsequent step. Regarding the protection motivation inferred from the copingand threat-appraisal (H3), the ANOVA revealed a (nearly) statistically significant increase in the inferred protection motivation when participants held a heavy clipboard, $F(1,116)=3.67, p=.06, \eta_{\mathrm{p}}{ }^{2}=.03$. This result derived from the fact that weight showed a stronger effect on coping- than on threatappraisal. In addition to the inferred protection motivation, I analysed the directly reported protection motivation. For this purpose, a moderated regression analysis was computed. The reported motivation served as criterion. Coping- and threat-appraisal were treated as continuous predictors, the clipboard's weight was included as a dummycoded variable $(0=$ light, $1=$ heavy $)$ serving as moderator. These three variables were initially centred to avoid problems of multicollinearity. Furthermore, they were crossed in all possible ways for the inter- 
Table 1 The effect of the clipboard's weight on the parameters of the PMT, inferred and reported protection motivation, and two social comparisons.

\begin{tabular}{|c|c|c|c|c|c|}
\hline & \multicolumn{2}{|c|}{ Light Clipboard } & \multicolumn{2}{|c|}{ Heavy Clipboard } & \multirow[b]{2}{*}{$p$} \\
\hline & $M$ & $S D$ & $M$ & $S D$ & \\
\hline Threat-appraisal & 0.64 & 1.73 & 1.15 & 2.20 & .172 \\
\hline Severity & 6.54 & 1.17 & 6.45 & 1.20 & .461 \\
\hline Vulnerability & 7.06 & 1.29 & 6.99 & 1.41 & .704 \\
\hline Rewards & 6.16 & 1.21 & 5.57 & 1.61 & .018 \\
\hline Coping-appraisal & 0.92 & 2.33 & 2.15 & 2.92 & .024 \\
\hline Self-efficacy & 4.81 & 1.43 & 5.99 & 1.75 & $<.001$ \\
\hline Response-efficacy & 6.82 & 1.56 & 7.00 & 1.47 & .598 \\
\hline Response costs & 4.90 & 1.59 & 4.34 & 1.86 & .153 \\
\hline \multicolumn{6}{|l|}{ Protection Motivation } \\
\hline Inferred motivation & 1.13 & 1.42 & 1.81 & 2.07 & .058 \\
\hline Reported motivation & 5.78 & 1.35 & 6.23 & 2.05 & .244 \\
\hline \multicolumn{6}{|l|}{ Social Comparison } \\
\hline Properness of skin cancer prevention & 0.33 & 2.10 & 0.54 & 2.18 & .704 \\
\hline Importance of a tanned skin & -1.54 & 2.15 & -1.75 & 2.38 & .522 \\
\hline
\end{tabular}

action analysis, resulting in seven predictors $^{2}$. In accordance with $\mathrm{H} 4$, the set of predictors explained a substantial amount of variance in the reported protection motivation, $R_{\text {adiusted }}^{2}=.57, p<.001$. Thereby, copingappraisal showed a significant predictive value, $b=.46, t=8.63, p<.001$, as well as the interaction term of coping-appraisal and

${ }^{2}$ Gender and age were not included as this would multiply the number of predictors and because a regression analysis with age, gender, and the age*gender term as predictors did not explain a significant amount of variance in the reported protection motivation, $R_{\text {adjusted }}^{2}<.01, p=.30$. weight, $b=.31, t=2.87, p=.01$. No further significant predictors were found, all $|t| \leq$ $1.45, p \geq .15$. Thus, coping-appraisal, but not threat-appraisal, influenced participants' reported motivation to perform proper skin cancer protection behaviour. I found that the higher the coping-appraisal, the higher the reported protection motivation. Moreover, the average increase (i.e., slope) for protection motivation was larger when the clipboard was heavy (Figure 2).

Finally, I analysed the impact of the clipboard's weight on two social comparison measures. In contrast to H5, weight was 


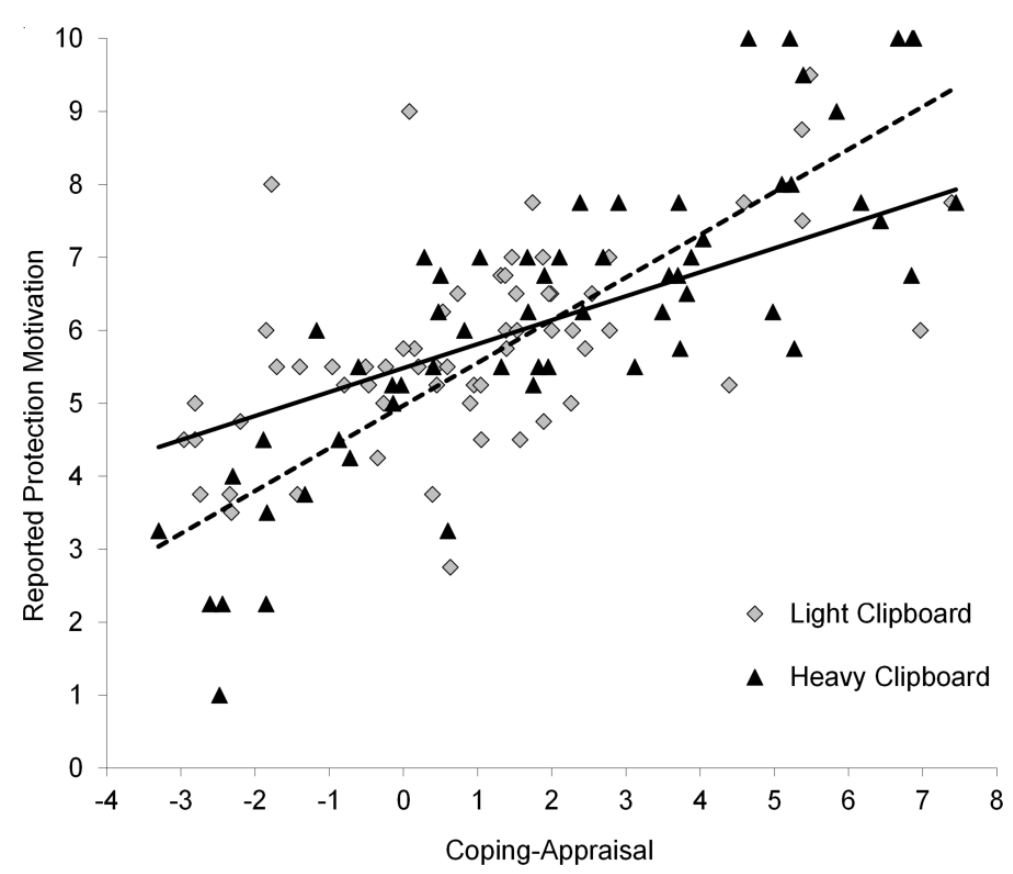

Figure 2 Scatter plot of reported protection motivation depending on coping-appraisal. Regression lines for the two clipboard conditions are marked (solid line: light clipboard; dashed line: heavy clipboard).

not only ineffective regarding the perceived properness of one's own skin cancer prevention compared to the skin cancer prevention of others, $F(1,116)=0.15, p=.70, \eta_{p}{ }^{2}<$ .01 . Weight did also not affect the reported importance of tanned skin, $F(1,116)=0.41$, $p=.52, \eta_{p}{ }^{2}<.01$. However, independent of the clipboard condition and participants' gender, the participants reported that tanned skin is less important for them compared to others, all $|t| \geq 3.28, p<.01, d \geq .60$.

\section{Discussion}

It appears to be common sense that the inputs to the PMT model include environ- mental as well as intrapersonal sources of information affecting the magnitude of the PMT parameters and, at the end, protection motivation. Thereby, the environmental sources include observational learning and verbal persuasion. Especially the latter is mainly addressed by researchers and practitioners searching for options to design persuasive communications. In this context, previous studies revealed that the effectiveness of persuasive communication depends on the degree to which individuals are intrinsically motivated to process a message (Cacioppo, Petty, Feinstein, \& Jarvis, 1996). Based on recent findings in the field of embodiment research, I raised the question 
whether changes in individuals' reported protection motivation can be elicited by incidental and very subtle bodily experiences instead of the common persuasive communication. The present study was conducted to test this possibility. In fact, the results showed that the incidental sensation of weight influenced participants' coping-appraisal and their motivation to perform proper skin cancer prevention.

Participants' coping-appraisal, but not threat-appraisal, was affected by the sensation of weight. The sensation of heaviness, compared to lightness, increased coping-appraisal by enhancing the reported self-efficacy. With respect to threat-appraisal, a decrease in perceived rewards was found when subjects held a heavy clipboard in their hands. However, the impact of weight on perceived rewards was not strong enough to influence the overall threat-appraisal. Nonetheless, the inferred protection motivation on the basis of the two appraisal types was increased by a heavy clipboard. Surprisingly, although a strong metaphorical link exists between the concrete concept of weight and the abstract concept of severity, I found no weight effect on the severity rating, contradicting previous findings (Kaspar, 2013). Thus, the present data are not fully compatible with the metaphor-oriented perspective on embodied cognition (cf. Williams et al., 2009; Ackerman et al., 2010). Consequently, a metaphorical relationship seems to be insufficient to entirely explain embodiment phenomena. Kaspar (2013) found a weight effect on the estimated effectiveness of drugs and the severity of their side effects when these ratings were made independently. However, when subjects simultaneously evaluated both drug characteris- tics, only the effectiveness showed a weight effect, indicating that the weight impact only touches the more salient judgement dimension. In the present study, copingappraisal and hence self-efficacy may have been in the participants' primary focus, hampering a weight effect on the severity rating. Similarly, although previous studies reliably showed that the experience of physical heaviness increases perceived importance of fair decision-making procedures (Jostmann et al., 2009) as well as the importance of a book's content (Chandler et al., 2012), I found no impact of weight on the reported importance of tanned skin when applying a social comparison. In contrast to previous studies, our participants did not judge the absolute importance of an issue but the relative importance compared to others. We can only speculate about the reasons for the absence of a weight effect in this context, but it seems conceivable that other information sources are more influential when it comes to a social comparison, such as upward and downward evaluation processes. In fact, independent of the clipboard's weight, participants reported that tanned skin would be less important for them compared to others. Thus, the influence of embodied cues, such as weight, appears to fluctuate across situations that vary regarding the set of environmental sources of information determining evaluation processes. It is a challenging task for future research to further scrutinize the boundary conditions for embodiment effects. Our knowledge is still very limited in this regard as already pointed out by Meier, Schnall, Schwarz, and Bargh (2012).

In addition to the main effects of weight on PMT parameters, the data showed that coping-appraisal, but not threat-appraisal, 
influenced participants' directly reported protection motivation. Higher coping-appraisal was accompanied by a higher willingness to carry out a more adequate skin cancer prevention. Importantly, the weight of the clipboard moderated the effect as heaviness increased this positive relationship. This result is remarkable as it demonstrates how incidental bodily sensations can positively affect one's motivation to behave more healthily. Consequently, weight is an important environmental source of information that is integrated into the cognitive elaboration of a specific health topic (cf. Figure 1). In this sense, the repertoire of potential inputs to the PMT is broader than hitherto assumed.

Consequently, basal bodily experiences are worth to be considered when focussing on health behaviour in the future. The present finding is of conceptual as well as practical significance. Firstly, we should partially rethink the current understanding of environmental inputs to the PMT model. It appears fruitful to explicitly consider body-environment interactions that affect higher cognitive functioning. Secondly, it has been unclear so far whether changes in self-reported measures by weight treatments actually reflect changes in one's perception of, for example, self-efficacy. It is also conceivable that weight only modifies the perception of the corresponding scale in a questionnaire by rescaling one's responses. If so, this will question the validity of such self-report measures in a pencil-and-paper administration mode, adding a new aspect to the ongoing debate about administration mode effects (cf. Gnambs \& Kaspar, 2014). However, if we assume that weight effects on judgements reflect real cognitive changes in a domain, the present findings will be noteworthy regard- ing potential therapeutic applications. Perhaps it will be particularly effective and efficient if we stimulate specific embodied information cues in therapeutic settings in order to change maladaptive behaviour, because bodily experiences are much more direct, less ambiguous, and require less cognitive evaluation than persuasive communication (Lee $\&$ Schwarz, 2012). In any case, the effect sizes of verbal communication should be compared with the potential effects of simple but specific body-related interventions. Finally, it should be investigated whether the impact of embodied cues on protection motivation really modifies the actual behaviour and how long-lasting the effects of such treatments are. Of course, this question is not specific to embodiment effects but generally relevant in the context of protection motivation. However, the intention-behaviour gap might be bridged more effectively by treatments addressing the body-environment interaction instead of persuasive communication, which focus on the verbal level. The present data provide some fruitful starting points for future research in this direction and indicate the value of an embodiment perspective on health-related behaviour.

Received February 23, 2015

\section{References}

Ackerman, J. M., Nocera, C. C., \& Bargh, J. A. (2010). Incidental haptic sensations of social judgements and decisions. Science, 328, 17121715.

Bishop, G. D. (1994). Health psychology: Integrating mind and body. Needham Heights, MA: Allyn $\&$ Bacon.

Boer, H., \& Seydel, E. R. (1996). Protection motivation theory. In M. Connor \& P. Norman (Eds.) Predicting Health Behavior. Buckingham: Open University Press. 
Cacioppo, J. T., Petty, R. E., Feinstein, J. A, \& Jarvis, W. B. G. (1996). Dispositional differences in cognitive motivation: The life and times of individuals varying in need for cognition. Psychological Bulletin, 119, 197-253.

Chandler, J. J., Reinhard, D., \& Schwarz, N. (2012). To judge a book by its weight you need to know its content: Knowledge moderates the use of embodied cues. Journal of Experimental Social Psychology, 48, 948-952.

Faul, F., Erdfelder, E., Lang, A. G., \& Buchner, A. (2007). G*Power 3: A flexible statistical power analysis program for the social, behavioral, and biomedical sciences. Behavior Research Methods, 39, 175-191.

Floyd, D. L., Prentice-Dunn, S., \& Rogers, R. W. (2000). A meta-analysis of research on protection motivation theory. Journal of Applied Social Psychology, 30, 407-429.

Gnambs, T., \& Kaspar, K. (2014). Disclosure of sensitive behaviors across self-administered survey modes: A meta-analysis. Behavioral Research Methods (online-first), 1-23. doi: 10.3758/ s13428-014-0533-4

Jostmann, N. B., Lakens, D., \& Schubert, T. W. (2009). Weight as an embodiment of importance. Psychological Science, 20, 1169-1174.

Kaspar, K. (2013). Embodied cognition is a weighty matter: Heaviness influences the perception of disease severity, drug effectiveness, and side effects. PLoS ONE, 8, e78307.

Kaspar, K., Jurisch, A., \& Schneider, M. (2015). Embodied cognition and humor: The impact of weight sensations on humor experience and the moderating role of gender. Current Psychology, (online first), 1-15. doi: 10.1007/s12144-0159304-3

Kaspar, K., König, S., Schwandt, J., \& König, P. (2014). The experience of new sensorimotor contingencies by sensory augmentation. Consciousness and Cognition, 28, 47-63.

Kaspar, K., \& Krull, J. (2013). Incidental haptic stimulation in the context of flirt behavior. Journal of Nonverbal Behavior, 37, 165-173.

Kaspar, K., \& Vennekötter, A. (2015). Embodied information in cognitive tasks: Haptic weight sensations affect task performance and processing style. Advances in Cognitive Psychology, 11, 64-76.

Lee, S. W. S., \& Schwarz, N. (2012). Bidirectionality, mediation, and moderation of metaphorical effects: The embodiment of social suspicion and fishy smells. Journal of Personality and Social Psychology, 103, 737-749.

Matarazzo, J. D. (1980). Behavioral health and behavioral medicine: Frontiers for a new health psychology. American Psychologist, 35, 807817.

McMath, B. F., \& Prentice-Dunn, S. (2005). Protection motivation theory and skin cancer risk: The role of individual differences in response to persuasive appeals. Journal of Applied Social Psychology, 35, 621-643.

Meier, B. P., Schnall, S., Schwarz, N., \& Bargh, J. A. (2012). Embodiment in social psychology. Topics in Cognitive Science, 4, 705-716.

Mermelstein, R. J., \& Riesenberg, L. A. (1992). Changing knowledge and attitudes about skin cancer risk factors in adolescents. Health Psychology, 11, 371-376.

Milne, S., Sheeran, P., \& Orbell, S. (2000). Prediction and intervention in health-related behavior: A meta-analytic review of protection motivation theory. Journal of Applied Social Psychology, 30, 106-143.

Norman, P., Boer, H., \& Seydel, E. R. (2005). Protection motivation theory. In M. Conner \& P. Norman (Eds.), Predicting health behaviour: Research and practice with social cognition models (pp. 81-126). Maidenhead: Open University Press.

Pechmann, C., Zhao, G., Goldberg, M. E., \& Reibling, E. T. (2003). What to convey in antismoking advertisements for adolescents: The use of protection motivation theory to identify effective message themes. Journal of Marketing, 67, 1-18.

Prentice-Dunn, S., McMath, B. F., \& Cramer, R. J. (2009). Protection motivation theory and stages of change in sun protective behavior. Journal of Health Psychology, 14, 297-305.

Rogers, R. W. (1983). Cognitive and physiological processes in fear-based attitude change: A revised theory of protection motivation. In J. Cacioppo \& R. Petty (Eds.), Social psychophvsiology: A sourcebook (pp. 153-176). New York. NY: Guilford.

Schneider, I. K., Rutjens, B. T., Jostmann, N. B., \& Lakens, D. (2011). Weight matters: Importance literally feels heavy. Social Psychological and Personality Science, 2, 474-478.

Schneider, S., \& Krämer, H. (2010). Who uses sunbeds? A systematic literature review of risk groups in developed countries. Journal of the 
European Academy of Dermatology and Venereology, 24, 639-648.

Williams, L. E., Huang, J. Y., \& Bargh, J. A. (2009).

The Scaffolded Mind: Higher mental processes

are grounded in early experience of the physical world. European Journal of Social Psychology, $39,1257-1267$.

Wilson, M. (2002). Six views of embodied cognition. Psychonomic Bulletin \& Review, 9, 625636.

\title{
TEÓRIA MOTIVÁCIE K OCHRANE Z TELESNÉHO HLADISKA: VPLYV VNIIMANIA HMOTNOSTI NA HODNOTENIE HROZBY, HODNOTENIE ZVLÁDANIA A MOTIVÁCIU K OCHRANE
}

\author{
K. K a s p a r
}

Súhrn: Štúdia ukazuje, ako telesné informácie obsiahnuté v kontexte prevencie rakoviny kože ovplyvňujú kognitívne zložky teórie motivácie k ochrane (PMT). Vnímanie hmotnosti sme manipulovali pomocou písania na l'ahkej vs. t'ažkej podložke. Vyššia hmotnost' zvyšovala priemernú sebaúčinnost' a hodnotenie zvládania u 120 respondentov, ale znižovala vnímané odplaty maladaptívneho správania. Naproti tomu, hmotnost' nemala vplyv na vnímanú škodlivost' maladaptívneho správania ani na význam opálenej pokožky. Výsledky sú len čiastočne v súlade s metaforicky orientovaným prístupom k telesnej kognícii. Okrem toho vyššie hodnotenie zvládania, no nie hodnotenia hrozby, zvyšovalo respondentmi vyjadrenú motiváciu k ochrane, zatial' čo túto koreláciu zvyšovala aj vnímaná hmotnost'. Vychádzajúc z výsledkov by sme mali rozšírit' spektrum vstupov prostredia, ktoré vplývajú na kognitívne parametre PMT. Výsledky nastol’ujú aj otázku validity sebavýpovedí pri administrácii spôsobom ceruzka-papier a výsledky poukazujú na využitie telesných vnemov v terapii. 